A $\mathbf{R}_{\text {EVIEW }}$

\title{
Uses and nutritional importance of mushroom
}

\begin{abstract}
Anjali Verma
Mushrooms are basically fungi, which have a fleshy and spore-bearing fruiting body. Mushrooms have been consumed as a part of normal diet from thousand of year due to their nutritional value. Mushroom relatively higher in good quality protein, low in total fat, higher in polyunsaturated fatty acids enriched with large amount of carbohydrate, valuable amount of fibres, significant amount of water, soluble vitamins as well as minerals. Studies revealed that mushrooms as the right source of protein to fight protein malnutrition in the cereal-dependent developing countries like India. Mushroom have also anticancerous, hypolipidemic, hypocholesterolemic, hypoglycemic, hypotensive immonomodulatory, haemato protective properties including properties of lowering blood sugars and blood pressure, anti bacterial, anti-viral and anti-fungal properties. Keeping in view all the above facts, its consumption should be encouraged.
\end{abstract}

Key Words : Mushroom, Fungi, Nutritional value, Developing countries

How to cite this article : Verma, Anjali (2015). Uses and nutritional importance of mushroom. Food Sci. Res. J., 6(1): 142-147. 